\title{
Space-filling and benthic competitions on coral reefs
}

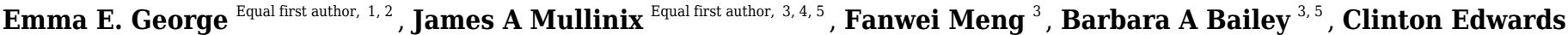 \\ ${ }^{6}$, Ben Felts ${ }^{3,5}$, Andreas F Haas ${ }^{7}$, Aaron Hartmann ${ }^{1,8}$, Benjamin Mueller ${ }^{9,10}$, Jim Nulton ${ }^{3,5}$, Ty Roach ${ }^{1,5}$, Peter \\ Salamon $^{3,5}$, Cynthia Silveira ${ }^{1,5}$, Mark Vermeij ${ }^{9,10}$, Forest Rohwer ${ }^{1,5}$, Antoni Luque ${ }^{\text {Corresp. 3, 4,5 }}$ \\ ${ }^{1}$ Department of Biology, San Diego State University, San Diego, California, United States \\ 2 Department of Botany, University of British Columbia, Vancouver, British Columbia, Canada \\ 3 Department of Mathematics and Statistics, San Diego State University, San Diego, California, United States \\ 4 Computational Science Research Center, San Diego State University, San Diego, California, United States \\ 5 Viral Information Institute, San Diego State University, San Diego, California, United States \\ 6 Scripps Institution of Oceanography, University of California, San Diego, San Diego, California, United States \\ 7 NIOZ Royal Netherlands Institute for Sea Research, Utrecht University, Texel, Netherlands \\ 8 Smithsonian National Museum of Natural History, Washington, DC, United States \\ 9 CARMABI Foundation, Willemstad, Curaçao \\ 10 Department of Freshwater and Marine Ecology/Institute for Biodiversity and Ecosystem Dynamics, University of Amsterdam, Amsterdam, Netherlands \\ Corresponding Author: Antoni Luque \\ Email address: aluque@sdsu.edu
}

Reef-building corals are ecosystem engineers that compete with other benthic organisms for space and resources. Corals harvest energy through their surface by photosynthesis and heterotrophic feeding, and they divert part of this energy to defend their outer colony perimeter against competitors. Here, we hypothesized that corals with a larger spacefilling surface and smaller perimeters increase energy gain while reducing the exposure to competitors. This predicted an association between these two geometric properties of corals and the competitive outcome against other benthic organisms. To test the prediction, fifty coral colonies from the Caribbean island of Curaçao were rendered using digital 3D and 2D reconstructions. The surface areas, perimeters, box-counting dimensions (as a proxy of space-filling property), and other geometric properties were extracted and analyzed with respect to the percentage of the perimeter losing or winning against competitors based on the coral tissue apparent growth or damage. The increase in surface space-filling dimension was the only significant single indicator of coral winning outcomes, but the combination of surface space-filling dimension with perimeter length increased the statistical prediction of coral competition outcomes. Corals with larger surface space-filling dimensions $\left(D_{s}>2\right)$ and smaller perimeters displayed more winning outcomes, confirming the initial hypothesis. We propose that the space-filling property of coral surfaces complemented with other proxies of coral competitiveness, such as life history traits, will provide a more accurate quantitative characterization of coral competition outcomes on 
coral reefs. This framework also applies to other organisms or ecological systems that rely on complex surfaces to obtain energy for competition 
1 Space-filling and benthic competitions on coral reefs

2

3 Emma E. George*1,2 ${ }^{*}$ James Mullinix*3,4,5, Fanwei Meng ${ }^{3}$, Barbara Bailey ${ }^{3,5}$, Clinton Edwards ${ }^{6}$, 4 Ben Felts $^{5}$, Andreas Haas ${ }^{7}$, Aaron C. Hartmann ${ }^{1,8}$, Benjamin Mueller ${ }^{9,10}$, Ty N.F. Roach ${ }^{1,5,11}$,

5 Peter Salamon ${ }^{3,5}$, Cynthia B. Silveira ${ }^{1,5}$, Mark J.A. Vermeij ${ }^{9,10}$, Forest L. Rohwer ${ }^{1,5}$, Antoni

6 Luque $^{3,4,5, \dagger}$

7

8

9

10

11

12

*Shared first authorship. ${ }^{+}$Corresponding author: aluque@sdsu.edu

${ }^{1}$ Department of Biology, San Diego State University, San Diego, CA, USA

${ }^{2}$ Department of Botany, University of British Columbia, Vancouver, BC, Canada

${ }^{3}$ Department of Mathematics and Statistics, San Diego State University, San Diego, CA, USA

${ }^{4}$ Computational Science Research Center, San Diego State University, San Diego, CA, USA

${ }^{5}$ Viral Information Institute, San Diego State University, San Diego, CA, USA

${ }^{6}$ Scripps Institution of Oceanography, University of California San Diego, San Diego, CA, USA ${ }^{7} \mathrm{NIOZ}$ Royal Netherlands Institute for Sea Research and Utrecht University, Texel, Netherlands ${ }^{8}$ Smithsonian National Museum of Natural History, Washington, DC, USA

${ }^{9}$ CARMABI Foundation, Willemstad, Curaçao

${ }^{10}$ Department of Freshwater and Marine Ecology/Institute for Biodiversity and Ecosystem Dynamics, University of Amsterdam, Amsterdam, The Netherlands

${ }^{11}$ Hawai' ${ }^{i}$ Institute of Marine Biology, University of Hawai' $i$, Kaneohe, HI, USA

+ Corresponding author: Antoni Luque

5500 Campanile Drive, San Diego, CA 92182, USA

Email: aluque@sdsu.edu 
31

32

33

34

\section{Abstract}

Reef-building corals are ecosystem engineers that compete with other benthic organisms for space and resources. Corals harvest energy through their surface by photosynthesis and heterotrophic feeding, and they divert part of this energy to defend their outer colony perimeter against competitors. Here, we hypothesized that corals with a larger space-filling surface and smaller perimeters increase energy gain while reducing the exposure to competitors. This predicted an association between these two geometric properties of corals and the competitive outcome against other benthic organisms. To test the prediction, fifty coral colonies from the Caribbean island of Curaçao were rendered using digital 3D and 2D reconstructions. The surface areas, perimeters, box-counting dimensions (as a proxy of space-filling property), and other geometric properties were extracted and analyzed with respect to the percentage of the perimeter losing or winning against competitors based on the coral tissue apparent growth or damage. The increase in surface space-filling dimension was the only significant single indicator of coral winning outcomes, but the combination of surface space-filling dimension with perimeter length increased the statistical prediction of coral competition outcomes. Corals with larger surface space-filling dimensions $\left(D_{s}>2\right)$ and smaller perimeters displayed more winning outcomes, confirming the initial hypothesis. We propose that the space-filling property of coral surfaces complemented with other proxies of coral competitiveness, such as life history traits, will provide a more accurate quantitative characterization of coral competition outcomes on coral reefs. This framework also applies to other organisms or ecological systems that rely on complex surfaces to obtain energy for competition. 


\section{Introduction}

54

55

56

57

58

Coral holobionts derive energy from photosynthesis - carried out by endosymbiotic algae — and heterotrophic feeding to build and maintain their calcium carbonate skeletons (Porter, 1976; Okie, 2013; Madl \& Witzany, 2014). The construction of the skeleton leads to the overall structure of the coral colony, which yields specific geometric properties (e.g., surface area, perimeter, volume), and thereby, coral holobionts shape the geometry of coral reefs from cellular to ecosystem scales. Corals also compete with organisms for limited reef space (Jackson, 1977; Meesters, Pauchli \& Bak, 1997), and these battles are fought along the border or perimeter of a coral colony at relatively small scales $(\mu \mathrm{m}-\mathrm{cm})$. Now, with modern $3 \mathrm{D}$ photogrammetry methods and 2D image merging software, the question of how coral morphology and its associated geometric properties relate to coral competition is explored at high resolution (Gracias \& Santos-Victor; Burns et al., 2015; Leon et al., 2015; Young et al., 2017; Ferrari et al., 2017; Hatcher et al., 2020).

Competitive interactions generally occur along the coral's perimeter where polyps interact with benthic organisms such as fleshy algae, calcifying algae, sponges and other corals (Jackson, 1977, 1979; Buss \& Jackson, 1979; Meesters, Wesseling \& Bak, 1996). At these interaction zones, a coral will either overgrow (win), be overgrown (lose), or display an apparent neutral interaction with the competitor species despite being in direct contact (Figure 1A) (Jackson \& Winston, 1982; Barott et al., 2012b; Swierts \& Vermeij, 2016). Loss of coral tissue also occurs due to disease and grazing (De Bakker et al., 2016; Rempel, Bodwin \& Ruttenberg, 2020). Corals use several strategies to compete with benthic organisms including overgrowth (McCook, Jompa \& Diaz-Pulido, 2001), the extension of sweeper tentacles and/or mesenterial filaments (Chornesky \& Williams, 1983; Nugues, Delvoye \& Bak, 2004; Galtier d'Auriac et al., 
2018), and the use of microbial/chemical warfare (Barott \& Rohwer, 2012; Roach et al., 2020).

Therefore, a longer coral perimeter increases the number of competitive interactions which requires increased defenses compared to a shorter perimeter. The energy and resources required to defend a perimeter are obtained via photosynthesis and heterotrophic feeding across the entire surface area of a coral colony (Porter, 1976), and then distributed through the coenosarc tissue throughout the colony (Rinkevich \& Loya, 1983; Oren, Rinkevich \& Loya, 1997; Henry \& Hart, 2005; Schweinsberg et al., 2015). As the surface area of a colony increases so does the number of polyps and the potential for energy acquisition and distribution (Jackson, 1979; Oren et al., 2001; Okie, 2013). Therefore, the relationship between perimeter length (i.e., energy needed for defense) and surface area (i.e., potential energy for defense and growth) may influence the result of the competition (e.g., win, lose or remain neutral).

Many coral geometric properties are dependent on coral morphology and life history.

Massive corals with smaller perimeter-to-surface area ratios demonstrate greater resilience to algal overgrowth compared to encrusting corals with larger perimeter-to-surface area ratios (Hughes, 1989; Tanner, 1995; Lirman, 2001). Corals belonging to both morphological groups invest energy in defense and may be aggressive competitors against other benthic organisms (Figure 1) (Swierts \& Vermeij, 2016). In contrast, corals with branching and pillar-like morphologies have minimized their perimeters at the base of the colony and invest energy in vertical growth following the "escape in height" strategy (Meesters, Wesseling \& Bak, 1996). Colony size has also been suggested to affect the outcome of coral-algal competition (Sebens, 1982; Ferrari, Gonzalez-Rivero \& Mumby, 2012). However, some studies found that small and large corals were more effective at competing against algae than medium sized corals (40-80 cm) (Barott et al., 2012a), while others found that medium size corals were better competitors 
99 (Swierts \& Vermeij, 2016). Additional studies are thus needed to determine the effect of coral 100 morphology on coral competition outcomes.

A key factor that has been overlooked when assessing coral competition outcomes is the

102

103

104

105

106

107

108

109

110

111

112

113

114

115

116

117

118

119

120

121

variation in the coral morphology and geometry across multiple structural levels (Zawada,

Dornelas \& Madin, 2019). Coral colonies with vastly different morphologies potentially display similar geometric properties, such as surface area or perimeter length, based on how the coral fills a specific space. For example, a small branching coral may have the same surface area as a large mounding coral due to the space-filling nature of the branching coral. Maximizing surface area within a defined space is common in biological systems that seek to increase energy transfer or biochemical activity such as the inner mitochondrial membrane (Faitg et al., 2020) and the intestinal villi in animals (Helander \& Fändriks, 2014). The opposite effect is expected for the coral perimeter where a decrease in space-filling would decrease the number of competitive interactions. Coral geometric properties are also dependent on the scale they are measured; surface area and perimeter length measured at the polyp-scale $(\mathrm{mm})$ may be larger than at the colony-scale (m) due to the small-scale features of the polyps (Holmes, 2008). Therefore, how much space a coral surface and perimeter fills at a defined scale will have important biological implications.

The space-filling properties of coral surfaces and perimeters are assessed using fractal dimension metrics, which determine how the volume, surface, and perimeter of an object fill a space across multiple scales (Mandelbrot, 1983; Murrary, 2001; Falconer, 2003; Reichert et al., 2017). Fractal dimensions have been used to analyze the geometry of natural systems from clouds and forests to plants, corals, and human organs (Mandelbrot, 1983; Basillais, 1997; Reichert et al., 2017). A physical property of an object—such as its volume, surface, or 
122 perimeter - is fractal if it satisfies two conditions (Halley et al., 2004). First, the fractal

123 dimension of the measured property is different than its Euclidean dimension, that is, 2D for a

124 surface or 1D for a perimeter. If the fractal dimension is larger than the Euclidean dimension,

125 then the property increases exponentially at smaller scales, and if it is smaller, the property

126 decreases exponentially as one magnifies the object (Peitgen, Jürgens \& Saupe, 1992; Cross et

127 al., 1993; Falconer, 2003; Martin-Garin et al., 2007). Second, the property must be self-similar or

128 statistically similar across scales. The analysis of this second condition is more challenging, and

129 many natural objects do not satisfy it (Panico \& Sterling, 1995). Studies often use the term

130 fractal when the first condition is met, even if the second condition is not confirmed or tested

131 (Murray, 2001; Halley et al., 2004). To avoid abusing the term fractal and misleading

132 interpretations, the term space-filling dimension will be used instead of fractal dimension.

133 Space-filling studies on corals have analyzed the texture and complexity of coral

134 structures at small and large scales (Fukunaga et al., 2019; Zawada, Dornelas \& Madin, 2019;

135 Sous et al., 2020). At the smallest scale, a box-counting method found that corallites $(<10 \mathrm{~mm})$

136 had a surface space-filling dimension of $\mathrm{D}_{\mathrm{s}}=0.8-1.6$ which is below the Euclidean dimension of

137 a surface $(\mathrm{D}=2)$; this small space-filing dimension was associated with the cavities of the

138 corallite, and the variance in space-filling dimension captured differences in corallite structures

139 (Martin-Garin et al., 2007). At the coral colony level, cube-counting methods on 3D coral

140 models found individual colonies to have space-filling dimensions less than 2.30, significantly

141 larger than the Euclidean dimension of a surface $\left(D_{s}=2\right)($ Fukunaga \& Burns, 2020). At the reef

142 level $(\sim 1 \mathrm{~km})$, a variation method found that the surface space-filling dimension was $\mathrm{D}_{\mathrm{s}}=\sim 2.28-$

143 2.61; this large value was associated to the rich texture of the reef (Zawada \& Brock, 2009). The

144 different levels of complexity is consistent with the space-filling dimension of the 2D perimeter 
$145\left(\mathrm{D}_{\mathrm{p}}\right)$ analyzed for large coral colonies $\left(10-100 \mathrm{~m}, \mathrm{D}_{\mathrm{P}} \sim 1.2\right)$ and coral reefs $\left(1 \mathrm{~km}, \mathrm{D}_{\mathrm{P}} \sim 1.6\right)$, both

146 displaying larger values than the Euclidean dimension of a curve, D = 1 (Bradbury \& Reichelt,

147 1983; Mark, 1984; Purkis, Riegl \& Dodge, 2006). However, space-filling dimension studies on

148 coral surfaces and perimeters at the colony level (millimeter to meter scales) have not been

149 examined in the context of coral competition.

150 This study explored how Euclidean geometric properties and space-filling dimension of

151 coral colonies were associated with coral competition outcomes (Figure 1A). We hypothesized

152 that corals with larger surface space-filling properties and shorter perimeters would have more

153 winning interactions than corals with smaller surface space-filling dimensions and longer

154 perimeters. To test this hypothesis, the space-filling dimensions and Euclidean geometric

155 properties of 50 coral colonies from the Caribbean island of Curaçao were obtained using 3D

156 photogrammetry (Figures $1 \mathrm{~B}$ and 1C) and analyzed using simple and multiple regression

157 methods. The results confirmed the hypothesis and showed significant relationships between

158 coral geometric properties, including surface space-filling dimension and the competition

159 outcome against benthic organisms.

\section{Materials \& Methods}

162

163

164

165

166

167

\section{Field sampling}

Fifty coral colonies were sampled randomly from eleven sites on the island of Curaçao (Figure 1B) using the CARMABI field permit (2012/48584). This included four sites in the eastern ( 9 colonies), four sites in the central (37 colonies), and three sites in the western (4 colonies) regions of the island. The samples from the central region were more numerous due to favorable diving conditions and corals were selected based on observations in the field. The coral 
168 species included Acropora palmata $(\mathrm{n}=2)$, Agaricia agaricites $(\mathrm{n}=2)$, Colpophyllia natans $(\mathrm{n}=$

169 5), Diploria labyrithiformis $(\mathrm{n}=4)$, Pseudodiploria strigosa $(\mathrm{n}=8)$, Montastraea cavernosa $(\mathrm{n}=$

170 10), Orbicella faveolata $(\mathrm{n}=12)$, and Siderastrea siderea $(\mathrm{n}=8)$ (Figure 1B). The samples were

171 skewed toward massive/boulder morphologies, reflecting coral species common in Curaçao (De

172 Bakker et al., 2016), and the number of colonies per species reflected their relative abundance in

173 the field. The depth ranged from 3.5 to $19 \mathrm{~m}$, but the sampling was not designed to capture

174 stratification. The 50 coral colonies were selected to reflect a range of sizes and interactions

175 including fleshy algae, calcifying algae, sponges, other corals and/or no competitors (overhangs

176 and sediment). The 50 colonies were photographed by SCUBA diving using a Canon Rebel T4i

177 with a 35-mm lens and two Keldan 800 lumen video lights to illuminate the corals uniformly. An

178 in-reef ruler was photographed with the corals to set the scale for the digital models, placing the

179 ruler along the perimeter of the coral colonies.

$2 D$ perimeter models and competition outcomes

The 2D perimeter models were generated by photographing sections of the coral

perimeter at close-range (Figure 1A). Multiple, overlapping pictures of the entire perimeter were

taken as close to the perimeter as possible (Figure 1C). The high-resolution ( $\mathrm{mm}$ ) overlapping

images of coral perimeters were stitched together to build each coral's 2D perimeter model

(Figure 1C) using Globalmatch and Guimosrenderer software, which was developed at Scripps

Institution of Oceanography using methods from Gracias \& Santos-Victor, 2000; Gracias \&

Santos-Victor, 2001; the software was accessed with permission through the Sandin Lab, Scripps

Institution of Oceanography. All zones of the perimeter were considered an interaction zone, 
191 interacting with sediment-dwelling organisms (e.g., anemones) and fleshy algae and/or sponges 192 were present on the underside of overhanging corals. Winning interactions were determined by coral tissue overgrowing or damaging the competitor, losing interactions were designated by apparent coral tissue damage or overgrowth by the competitor, and neutral interactions were identified if neither the competitor nor the coral showed signs of damage or overgrowth (Figure 1A). The interaction between corals and other competing organisms was outlined using a onepixel pen tool in Adobe ${ }^{\circledR}$ Photoshop ${ }^{\circledR}$ CC 2014 at the edge of the coral tissue (Figure 1C). The one-pixel wide outline was colored in separate RGB channels to designate competition outcomes: red (coral losing), green (coral winning), and blue (neutral). The fraction of red, green, and blue pixels was used, respectively, to obtain the percentage of losing $(\% \mathrm{~L})$, winning $(\% \mathrm{~W})$, and neutral $(\% \mathrm{~N})$ interactions around a coral perimeter.

\section{$3 D$ coral models and coral space-filling dimensions}

Structure-from-Motion (SfM) photogrammetry was used to create 3D coral models. Autodesk ${ }^{\circledR}$ ReMake ${ }^{\circledR}, 2016$ was utilized for 3D construction of coral models (Burns et al., 2015; Leon et al., 2015) (Figure 1C) and measurement of geometric properties of corals such as perimeter, surface area, and volume (Naumann et al., 2009; Lavy et al., 2015). The initial coral renderings were investigated visually to identify patches of dead coral in the surface (Figure S1) and these patches without coral tissue were removed from the 3D models. The resolution of the the median area of the triangles in the mesh of the 3D models. Coral space-filling dimension was calculated using a box counting method (Falconer, 213 2003). The algorithm developed was generalized to multidimensional objects. The boxes 
214 corresponded to rectangles in 2D images and parallelepipeds in 3D images, and the initial box

215 corresponded to the smallest axis-aligned bounding box containing the point cloud for each coral

216 model. The logarithm of the number of boxes was plotted against the logarithm of the box size,

217 and the space-filling dimension $D$ was extracted from the slope of the linear regression (Eq. S1,

218 Figure S2). The algorithm was validated against known fractal objects (Peitgen, Jürgens \&

219 Saupe, 1992; Cross et al., 1993; Falconer, 2003), leading to errors smaller than 3\%. The method

220 was validated against fractals that were generated using seven recursion levels, and box-counting

221 used at least seven bisections (Table S1). This error value was used as an upper theoretical error

222 for the estimated space-filling dimension. The perimeter space-filling dimension $\left(\mathrm{D}_{\mathrm{P}}\right)$ was

223 calculated from the 2D models by applying the generalized box-counting algorithm using

224 rectangular boxes. The $2 \mathrm{D}$ models were used due to their higher resolution with respect to the 3D

225 model. The 2D models allowed a minimum of ten bisections in the algorithm $(<1 \mathrm{~mm}$

226 resolution), that is, a space-filling analysis across scales encompassing three orders of magnitude

$227\left(2^{10}=1,024\right)$. The surface space-filling dimension $\left(D_{S}\right)$ was calculated from the 3D models

228 applying the generalized box-counting algorithm using parallelepiped boxes. A minimum of five

229 bisections in the algorithm was used. Nonparametric bootstrap resampling was used to construct

$23095 \%$ bias-corrected and accelerated $(\mathrm{BCa})$ confidence intervals on the slope $(D)$ of the coral

231 models (Efron \& Tibshirani, 1994). Self-similarity over multiple scales was not tested and

232 therefore, the fractality of the coral surface and perimeter was not determined. See

233 Supplementary Material for additional details.

234

235

Coral geometric properties: perimeter, surface area, volume, polyp size, and patch area 
237 the 3D models. Both measurements were used because they had complementary advantages and

238 disadvantages. The 2D reconstructions displayed higher-resolution at finer scales but distorted

239 the overall shape of the perimeter due to the reconstructions. The 3D models captured the

240 perimeter shape more accurately but the resolution at finer scales was lower, limiting the

241 multiscale analysis. The perimeter length in the $2 \mathrm{D}$ reconstructions were obtained from the

242 Richardson algorithm with a ruler size of $1 \mathrm{~mm}$ (Mandelbrot, 1983; Falconer, 2003). For volume

243 calculations, the fill tool in Autodesk ${ }^{\circledR}$ Remake ${ }^{\circledR}$ was used to create a mesh that closed the area

244 outlined by the perimeter of the $3 \mathrm{D}$ coral model, and then the volume of the 3D model was

245 measured. Patches of dead tissue within the coral colonies were removed from 18 coral models

246 to calculate total coral surface area and dead tissue patch area. Perimeter, surface area, and

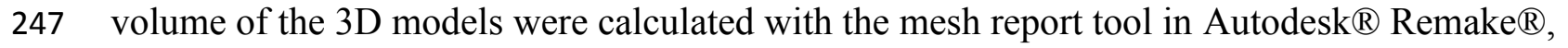

248 2016. Polyp diameters were measured from the high-resolution perimeter images using ImageJ

$2491.47 \mathrm{v}$, and 10 polyp diameters per colony were averaged. Additional details are provided in

250 Supplementary Material, and the measurements for each variable are available in Source Data 1.

252 Correlation with single variables

A least-squares linear regression was used to compare the percentages of losing $(\% \mathrm{~L})$ and

254

255

256

257

258

259 winning $(\% \mathrm{~W})$ perimeter with respect to thirteen coral variables: depth $(\mathrm{d})$, polyp diameter $\left(\mathrm{P}_{\mathrm{d}}\right)$, volume $(\mathrm{V})$, surface area (SA), volume-to-surface area (V/SA), surface area-to-polyp area ratio $\left(\mathrm{SA}_{\text {polyp}}\right)$, perimeter space-filing dimension $\left(\mathrm{D}_{\mathrm{P}}\right)$, surface space-filling dimension $\left(\mathrm{D}_{\mathrm{S}}\right), 2 \mathrm{D}$ perimeter length obtained from Richardson's algorithm $\left(\mathrm{P}_{\mathrm{R}}\right)$, perimeter length obtained from 3D models $\left(\mathrm{P}_{3 \mathrm{D}}\right), 3 \mathrm{D}$ perimeter-to-polyp size ratio $\left(\mathrm{P}_{\text {polyp }}\right), 2 \mathrm{D}$ perimeter-to-surface area ratio $\left(\mathrm{P}_{\mathrm{R}} / \mathrm{SA}\right)$, and 3D perimeter-to-surface area ratio $\left(\mathrm{P}_{3 \mathrm{D}} / \mathrm{SA}\right)$. These variables included absolute 
260 values of each coral colony as well as relative values with respect to polyp size since the energy

261 and nutrient harvesting in the colony is obtained through polyps. The neutral interactions were a

262 small fraction and were not studied in detail (Figure 2). Nonparametric bootstrap resampling was

263 used to construct 95\% bias-corrected and accelerated (BCa) confidence intervals to validate the

264 statistical significance of the slope p-values (Efron \& Tibshirani, 1994). The outputs of the

265 statistical analysis are available in Source Data 2.

266

267

Multivariate regression using random forests

A multivariate regression analysis of the competitive outcomes as a function of the

measured variables was performed applying the statistical learning method random forest using

the R package randomForest (Liaw \& Wiener, 2002). Random forest is a non-parametric

existence of correlations between input variables does not impact the output of random forest.

273 Such variables are implicitly grouped with one dominating variable and the other variables as

274

275

276

277

278

279

280

281

282 surrogates (James et al., 2000). Two independent approaches were used with random forest.

First, all measured variables were incorporated in the initial model. The replication of the analysis using 100,000 random forest trials, however, indicated that the selection of significant variables and percentage explained variance was not robust. This was due to relatively small dataset (50 independent coral competitive outcome measurements) compared to the number of variables (14 in total: the 13 variables used in the univariate analysis plus the categorical species variable). Second, a bottom-up alternative approach was followed. The statistical model for each response $(\% \mathrm{~L}$ and $\% \mathrm{~W})$ was constructed by first selecting the variable with the highest univariate correlation and creating a random forest $(\mathrm{RF})$ model. The remaining variables were added to the 
283 model using the following procedure. A variable was chosen from the unselected variables and

284 added to the RF model, and the percent explained variance for this model was calculated. The

285 variable was then removed from the model, and the next variable was added. This was repeated

286 for all unselected variables, and the variable with the largest percent explained variance was

287 marked as selected. The model was reset, and the entire procedure was repeated until 10,000

288 iterations were completed. The likelihood of variable selection was calculated as (\# times

289 selected $) /(10,000)$. The variable with the highest likelihood of selection was added to the model,

290 and the total number of variables in the model was increased. This procedure was repeated until

291 the RF model contained all variables.

292

293 Results

294 Coral competition outcomes

295 The coral colonies sampled displayed a range of percentage of losing perimeter from $8 \%$

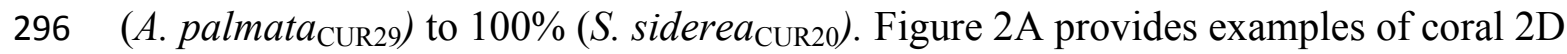

297 perimeters and 3D models displaying small (20\%) to large (92\%) percentage of losing perimeter.

298 Corals displayed an average of $60 \%$ losing, $29 \%$ winning, and $11 \%$ neutral interactions along the

299 perimeter (Figure 2B and Table S2). Among species sampled in five or more colonies, S. siderea

300 displayed the largest percentage of losing perimeter (81\%), followed by P. strigosa (69\%), M.

301 cavernosa $(58 \%)$, and $O$. faveolata (56\%) (Figure 2C). An inverse trend was found regarding the

302 percentage of winning perimeter: O. faveolata (33\%), M. cavernosa (23\%), P. strigosa (19\%),

303 and S. siderea (12\%). The percentage of neutral perimeter was considerably smaller and

304 followed a different trend: M. cavernosa (19\%), P. strigosa (12\%), O. faveolata (11\%), and $S$.

305 siderea $(8 \%)$. Corals were losing a major fraction of their perimeters, and the neutral regions 
306

307

308

309

310

311

312

313

314

315

316

317

318

319

320

321

322

323

324

325

326

327

328

represented the smallest fraction among the three competitive outcomes. On average, S. siderea was the most vulnerable species, while $O$. faveolata was the most successful competitor.

Space-filling dimensions of the coral perimeter and coral surface

The space-filling dimension, defined as the box-counting dimension, was interpreted with respect to the Euclidean dimension (ED) of the property measured, that is, $\mathrm{ED}_{\mathrm{S}}=2$ for the surface and $\mathrm{ED}_{\mathrm{P}}=1$ for the perimeter. If the surface space-filling dimension $\left(\mathrm{D}_{\mathrm{S}}\right)$ of a coral was equivalent to the Euclidean dimension $\left(\mathrm{ED}_{\mathrm{S}}=2\right)$, then the surface would not depend strongly on the resolution of measurement, and the coral would be studied as a classical Euclidean object. If a coral instead had a surface space-filling dimension larger than two $\left(D_{S}>2\right)$, then the surface would be more complex, displaying additional features at higher resolutions. In this case, the total surface of the coral measured at $1 \mathrm{~mm}$ scale would be larger than at $1 \mathrm{~m}$ scale. Finally, if a coral had a surface space-filling dimension smaller than two $\left(\mathrm{D}_{\mathrm{S}}<2\right)$, it would lose features as the resolution increased due to the presence of patches devoid of coral polyps (Figure S1), and the total surface area would be smaller at higher resolutions. These same ideas also apply to the perimeter where the Euclidean dimension is $\mathrm{ED}_{\mathrm{P}}=1$.

The perimeter space-filling dimensions $\left(\mathrm{D}_{\mathrm{P}}\right)$ measured from the $2 \mathrm{D}$ perimeter reconstructions of the 50 corals were close to the Euclidean value $\mathrm{D}_{\mathrm{P}} \sim 1$, which was contained within the 95\% confidence interval for all corals except for three colonies (Figure 3A). Incorporating the theoretical error from the space-filling algorithm $(3 \%)$ placed the three colonies within the Euclidean value: $O$. faveolata $_{\mathrm{CUR} 34}(\mathrm{DP}=1.00 \pm 0.03)$, S. siderea $_{\mathrm{CUR} 54},(\mathrm{DP}=$ $0.99 \pm 0.03)$, and $A$. palmata $_{\mathrm{CSA} 142}(\mathrm{DP}=0.99 \pm 0.03)$. The average space-filling dimension combining all corals was $\left\langle\mathrm{D}_{\mathrm{P}}\right\rangle=1.00 \pm 0.03(\mathrm{SE})$, and the mean values of individual corals 
329 ranged from $0.97(-2.65 \%)$ to $1.01(+1.17 \%)$ with respect to the average perimeter space-filling

330 dimension (1.00). Coral perimeters with high $\left(D_{P}=1.01 \pm 0.03\right)$, medium $\left(D_{P}=1.00 \pm 0.01\right)$, and

331 low $\left(D_{P}=0.99 \pm 0.01\right)$ space-filling dimension $( \pm S E)$ did not display any different salient

332 geometric features (Figure 3B). Thus, the apparently convoluted perimeters of coral colonies had

333 a space-filling dimension consistent with the Euclidean dimension. Small differences in the

334 space-filling dimension were therefore not geometrically relevant.

335 The surface space-filling dimensions $\left(D_{S}\right)$ for the 50 coral colonies were also close to the

336 Euclidean value $\mathrm{D}_{\mathrm{S}} \sim 2$, which was contained within the $95 \%$ confidence interval for all corals

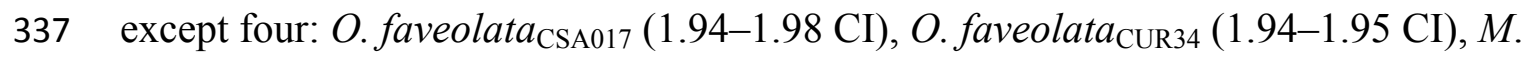

338 cavernosa $_{\mathrm{CUR} 40 \_2}(1.90-1.94 \mathrm{CI})$, and $O$. faveolata fuR9 $_{\mathrm{CU}}(1.84-1.88 \mathrm{CI})$. When considering the

339 error of the space-filling algorithm $(\sim 3 \%)$, O. faveolata $_{\mathrm{CSA} 017}\left(\mathrm{D}_{\mathrm{S}}=1.94 \pm 0.06\right)$ and $O$.

340 faveolata $_{\mathrm{CUR} 34}\left(\mathrm{D}_{\mathrm{S}}=1.94 \pm 0.06\right)$ were statistically compatible with the Euclidean value, while

$341 M$. cavernosa $\mathrm{CUR}_{\mathrm{CU} \_2}\left(\mathrm{D}_{\mathrm{S}}=1.90 \pm 0.06\right)$ and $O$. faveolata fUR9 $_{\mathrm{C}}\left(\mathrm{D}_{\mathrm{S}}=1.86 \pm 0.06\right)$ remained lower.

342 The average space-filling dimension combining all corals was $\left\langle\mathrm{D}_{\mathrm{s}}\right\rangle=2.00 \pm 0.06( \pm \mathrm{SE})$. The

343 mean value of individual corals ranged from $1.84(-8.01 \%)$ to $2.13(+6.32 \%)$ with respect the

344 average surface space-filling dimension. Corals colonies displayed significant geometrical

345 differences as illustrated in Figure 3C for corals with high $(2.08 \pm 0.04)$, medium $(2.01 \pm 0.04)$,

346 and low $(1.90 \pm 0.03)$ surface space-filling dimensions. Corals with high surface space-filling

347 dimensions had little to no patches of missing coral tissue and displayed a more texturized

348 surface. Coral colonies with low space-filling dimensions instead displayed patches of missing

349 coral tissue (Figure S1), peninsula-like perimeters, and/or smoother/flatter surfaces (Figure 3).

350 Thus, the surface of coral colonies had space-filling dimensions near the Euclidean value, but

351 they displayed a much larger relative variance with respect to the perimeter space-filling 
352 dimension and several contained salient geometric features between low and high surface space-

353 filling dimensions.

354

355

356

357

358

359

360

361

362

363

364

365

366

367

368

369

370

371

372

373

374

Relationship between competitive outcomes and individual geometric variables

The percentage of losing $(\% \mathrm{~L})$ and winning $(\% \mathrm{~W})$ perimeter was studied as a function of the 12 geometric and biological variables using linear regression analysis (Source Data 2). The surface space-filling dimension was the only variable that displayed a strong significant correlation with $\% \mathrm{~L}$ or $\% \mathrm{~W}$ (Figures $4 \mathrm{~A}$ and $4 \mathrm{~B})$. Percentage of losing perimeter $(\% \mathrm{~L})$ correlated negatively with surface space-filling dimension (slope $=-145 \pm 45, \mathrm{R}^{2}=0.18$, $\mathrm{p}$-value $\left.=0.0021^{* *}\right)$, while percentage of winning perimeter $(\% \mathrm{~W})$ correlated positively with surface space-filling dimension ( slope $=144 \pm 45, \mathrm{R}^{2}=0.18$, $\mathrm{p}$-value $=0.0023^{* *}$ ). This was consistent with $\% \mathrm{~W}$ being negatively correlated with $\% \mathrm{~L}\left(\right.$ slope $=-0.9 \pm 0.1, \mathrm{R}^{2}=0.8, \mathrm{p}$-value $=2.2 \times 10^{-}$ $16 * * *$ ) (Figure S3). The surface area was the only other variable that came close to being significant, but it displayed a much weaker correlation with the competitive outcomes $\left(\mathrm{R}^{2}=0.09\right.$, $\mathrm{p}$-value $=0.05)($ Figure $\mathrm{S} 4)$. Thus, the mean values of the surface space-filling dimension displayed the strongest correlation with competitive outcomes, capturing $18 \%$ of the variance (Figures $4 \mathrm{~A}$ and $4 \mathrm{~B}, \mathrm{R}^{2}=0.18$ ).

Coral competitive outcomes and geometric variables were also analyzed separately for species represented by more than five sampled colonies: Orbicella faveolata $(n=12)$,

Montastraea cavernosa $(\mathrm{n}=10)$, Pseudodiploria strigosa $(\mathrm{n}=8)$, and Siderastrea siderea $(\mathrm{n}=7)$.

All species displayed a decrease in the percentage of losing perimeter $(\% \mathrm{~L})$ as surface spacefilling dimension increased (Figure S5). However, the relationship was statistically significant only for $S$. siderea, and the variance in the other species was too large with respect to the sample 
375 size. No other variables significantly correlated with $\% \mathrm{~L}$ or $\% \mathrm{~W}$ in the species-specific analysis.

376

377

378

379

380

381

382

383

384

385

386

387

388

389

390

391

392

393

394

395

396

397

\section{Importance of combined geometric variables in coral competition outcomes}

The bottom-up random forest (RF) model approach yielded a robust, repeatable

construction of the non-parametric statistical model. For the percentage losing perimeter $(\% \mathrm{~L})$,

the addition of perimeter $\left(\mathrm{P}_{3 \mathrm{D}}\right)$ and species $(\mathrm{S})$ to the surface space-filling dimension $\left(\mathrm{D}_{\mathrm{s}}\right)$ sharply increased the percentage explained variance in the model to $(23 \pm 1) \%$ (Figure 4C). Adding more variables, however, decreased the percentage of variance explained in the model due to the limited dataset size $(n=50)$. The selection of perimeter $\left(P_{3 D}\right)$ and species $(S)$ as the second and third most important variables, respectively, was very robust with a frequency close to $100 \%$ (Figure 4E). For the percentage winning perimeter $(\% \mathrm{~W})$, the addition of perimeter $\left(\mathrm{P}_{3 \mathrm{D}}\right)$ and perimeter-to-surface area $\left(\mathrm{P}_{3 \mathrm{D}} / \mathrm{SA}\right)$ to surface space-filling dimension $\left(\mathrm{D}_{\mathrm{S}}\right)$ sharply increased the percentage explained variance in the model to $(25 \pm 2) \%$ (Figure $4 \mathrm{D})$. The addition of variables involving coral volume-to-surface area (V/SA), surface area (SA), sampling depth (d), and projected perimeter-to-surface area $\left(\mathrm{P}_{\mathrm{R}} / \mathrm{SA}\right)$ led to a maximum percentage explained variance of $(32 \pm 1) \%$. The addition of more variables decreased the percentage variance explained due to the limited size of the dataset $(n=50)$. The selection of the perimeter $\left(P_{3 D}\right)$ as the second most important variable had a frequency of $100 \%$ (Figure $4 \mathrm{~F}$ ). The subsequent variables were not always selected in the same order of importance. However, in both analyses ( $\% \mathrm{~L}$ and $\% \mathrm{~W})$, the frequency of the least important variables selected were robust (Figures 4E and 4F). In particular, the perimeter space-filling dimension was selected as the least relevant variable in predicting coral competitive outcomes. This is consistent with the fact that no apparent geometric features were observed in the initial space-filling analysis of the perimeter (Figure 3). The results for the 
398 percentage losing and winning perimeters therefore indicated that the surface space-filling

399 dimension and perimeter length were the most important variables associated to the coral 400 competition outcomes.

401

402

Hierarchical analysis of coral competitive outcomes and coral geometry

403

When analyzing the hierarchy of the most relevant geometric variables for the percent of

404

losing perimeter $(\% \mathrm{~L})$ and winning perimeter $(\% \mathrm{~W})$, the primary node corresponded to the

405

surface space-filling dimension, and the secondary node was the perimeter from 3D models

406

(Figure 5). For the percent losing tree (Figure 5A), corals with $\mathrm{D}_{\mathrm{S}} \geq 2$ had the smallest $\% \mathrm{~L}$, and

407

among those, corals with $\mathrm{P}_{3 \mathrm{D}}<91 \mathrm{~cm}$ formed the group with the smallest percentage of losing

408

perimeter (24\%). A similar trend was found for the percent winning tree (Figure 5B): corals with

$\mathrm{D}_{\mathrm{S}} \geq 2$ and $\mathrm{P}_{3 \mathrm{D}}<91 \mathrm{~cm}$ had largest percentage of winning perimeter $(84 \%)$. For corals with $\mathrm{D}_{\mathrm{S}}<$

2 , smaller perimeters related to increased $\% \mathrm{~L}$ and decreased $\% \mathrm{~W}$ compared to corals with $\mathrm{D}_{\mathrm{S}}<2$

411

and larger perimeters. The fact that small perimeters can have opposite effects depending on the

412

surface space-filling dimension may explain why the perimeter length did not display a

413

correlation in the single variable analysis. Overall, these results suggest that corals with a surface

space-filling dimension $D_{S} \geq 2$ and relatively small perimeters have better competition outcomes

415 (i.e., less losing and more winning outcomes).

416

\section{Discussion}

418

419

420

Hypothesis: surface space-filling dimension and coral competitive edge

This study hypothesized that an increase in surface space-filling dimension and a reduction in perimeter would be associated with successful coral competitive outcomes. The 
421 rational was that the complexity added by the surface space-filling dimension would increase the

422 potential for energy harvesting without necessarily leading to a larger coral colony and exposing

423 more perimeter to benthic competitors. The univariate, statistical analysis indicated that the

424 surface space-filling dimension was the most important variable associated to percentage of

425 winning and losing perimeter, and the multivariate analysis confirmed that the perimeter was the

426 second most important variable (Figure 4). The selection of these variables and their associated

427 trends with coral competitive outcomes supported the initial hypothesis (Figure 5). Therefore,

428 this study indicates a potential causality of higher surface space-filling dimensions in the

429 resilience and health of corals, and longitudinal studies that assess changes in competitive

430 outcomes over time will be necessary to confirm this prediction.

431

432

Relationship between coral geometry and coral interaction outcomes

The optimal combination of coral geometric properties explained $(23 \pm 2) \%$ to $(32 \pm 1) \%$

of the coral interaction outcomes, where the surface space-filling dimension was the best single indicator for the percentage of losing or winning perimeter (Figure 4). The space-filling

436 dimension or complexity of a coral surface likely reflects the ability to harvest energy through

437 heterotrophic feeding of individual polyps and photosynthesis carried out by the endosymbiotic

438 Symbiodiniaceae (Bachar et al., 2007). Losing corals had surface space-filling dimensions below 439 the Euclidean dimension $\left(\mathrm{D}_{\mathrm{S}}<2\right)$, and some of the reduced complexity was associated with 440 patches (absence of coral tissue) and small, smooth colony surfaces (Figure 3C, Figure S1). The 441 patches of missing coral tissue reduce the network of polyps, thus impeding the allocation of 442 resources. However, patch area alone failed to correlate with either competitive outcomes or 443 space-filling dimension (Figure S6), and significant trends between competitive outcomes and 
444 space-filling dimension were also observed in corals without patches (Figure S7). Therefore, the

445 patches of dead tissue are only one of multiple features relevant to coral competitive outcomes

446 measured by the space-filling dimension metric.

447 The perimeters of coral colonies with low space-filling dimensions also displayed large

448 peninsula-like shapes that increase the perimeter length along with the potential number of

449 competitor interactions (Figure S1). The two features, dead tissue patches and perimeter

450 peninsulas, may elucidate the low surface space-filling dimension of corals with larger

451 percentages of dead or overgrown tissue along the perimeter. Conversely, winning corals had

452 surface space-filling dimensions larger than the Euclidean dimension $\left(\mathrm{D}_{\mathrm{S}}>2\right)$ which translated

453 into large surface areas with more complex surface features and no patches (Figure 3C). This

454 implies a denser network of polyps to feed and harvest energy, thus explaining the larger

455 percentage of positive competitive outcomes for coral colonies with larger surface space-filling

456 dimensions.

457 In addition to surface space-filling dimension, the perimeter length was another

458 significant geometric variable in coral competition outcomes (Figure 4). Corals with larger

459 surface space-filling dimensions and smaller perimeters displayed increased \%W and decreased

$460 \% \mathrm{~L}$ (Figure 5). This supports the hypothesis that more energy is required to defend a longer

461 perimeter, and that corals with complex surfaces may provide additional resources for defense

462 compared to corals with less complex surfaces. However, smaller perimeters appeared

463 unfavorable to corals with surface space-filling dimensions smaller than two (Figure 5). This is a

464 surprising result, but the corals in these categories had the highest \%L (96\%) and lowest \%W

$465(19 \%)$. The corals also displayed relatively smooth perimeters with no peninsula-like features

466 compared to corals with $\mathrm{D}_{\mathrm{S}}<2$ and longer perimeters. The loss of perimeter features potentially 
467 correspond to significant coral tissue damage around the perimeter, and despite the reduced

468 perimeters, the corals may have lost too much surface complexity, thus reaching an unavoidable

469 trajectory to be overgrown by competitors. However, the dynamics of coral competitive

470 outcomes need further investigation to determine how these coral geometrical properties relate to

471 the resilience of corals over time.

472 Surface area had significant correlations with competition outcomes (Figure S4), but the

473 relationship was weaker than the surface space-filling dimension. This suggests that the increase

474 in surface area per $\mathrm{cm}^{2}$ captured by the space-filling dimension provides a more accurate account

475 for coral competitiveness than surface area alone, and that a larger surface area also does not

476 necessarily correspond to a higher space-filling dimension. For example, Orbicella

477 faveolata $_{\mathrm{CUR} 36}$ displayed a higher space-filling dimension than Orbicella faveolata $_{\mathrm{CUR} 08}$ and also

478 had a greater percentage of winning perimeter despite its smaller surface area (smaller colony).

479 The information regarding the relative increase in effective surface area per $\mathrm{cm}^{2}$ captured by the 480 space-filling dimension justifies the higher explained variance obtained by this metric compared 481 with surface area alone.

Species-specific life traits also played a role in competition outcomes since coral species was a relevant variable in the multivariate analysis for the percentage of losing perimeter (Figure photochemical efficiency and symbiont density compared to other species such as $M$. cavernosa, P. strigosa and S. siderea (Muthiga \& Szmant, 1987; Warner, Fitt \& Schmidt, 1996; Castillo et al., 2014; Scheufen, Iglesias-Prieto \& Enríquez, 2017), and out of these species, O. faveolata 
490 displayed the largest average surface space-filling dimension, suggesting that the space-filling

491 property of $O$. faveolata is maximized for photosynthesis. The greater photosynthetic capabilities

492 of $O$. faveolata may also explain the competitive outcome results, where O. faveloata had the

493 greatest percentage of winning interactions compared to the other three species. The two species,

$494 P$. strigosa and $S$. siderea, are considered weedy coral species, and they had the greatest

495 percentage of losing perimeter (Toth et al., 2019). On the other hand, Montastraea cavernosa is a

496 slow growing species (Manzello et al., 2015) that had few losing interactions, suggesting that

497 slower growing corals invest more resources in protecting their perimeters, as observed in the

498 increased sweeper tentacles near interaction zones of M. cavernosa colonies (Chornesky \&

499 Williams, 1983). This energy tradeoff between growth and defense directly affects the

500 competition outcomes along the perimeter of a coral (Swierts \& Vermeij, 2016), and different

501 coral species have evolved various strategies to balance this tradeoff. This study focused on

502 mounding morphologies (Figure 1), and additional data for species with other morphologies and

503 life traits will be necessary to confirm the relationship between geometric properties and coral

504 competitive outcomes.

505 The combination of surface space-filling dimension, perimeter, and additional geometric

506 properties were able to explain up to $30 \%$ of the variance in the coral competition outcomes.

507 Methodologies that improve the 3D coral model reconstruction and increase the signal-to-noise

508 ratio may lead to geometric analyses with higher explained variances. Additionally, other factors

509 are known to be relevant in determining the outcomes of coral space competition with other

510 sessile organisms. Physiological factors display strong codependences with the geometry

511 (Jackson, 1979; Merks et al., 2004; Zawada, Dornelas \& Madin, 2019), but another factor that

512 may be orthogonal and complementary to the geometry is the assembly of microbes associated 
513 with the coral and its competitors. Microbes and their associated metabolites have been shown to

514 be important in mediating the ecological interaction of corals with other benthic organisms (Haas

515 et al., 2016; Silveira et al., 2019; Roach et al., 2020), along with coral disease (De Bakker et al.,

516 2016). The combination of geometry, species-specific life traits, and microbial properties will

517 improve the prediction of coral competition outcomes in future studies.

518

519 Coral space-filling dimensions over multiple scales

520 The space-filling dimensions of the coral colonies obtained from this study were also

521 compared to prior space-filling or fractal studies encompassing smaller (coral septa or polyp) and

522 larger (reef) scales (Figure 6). The qualitative analysis indicated that the space-filling dimension

523 of corals increased from millimeter to kilometer scales, where the space-filling dimensions were

524 closer to the Euclidean dimensions at the colony scale investigated here. This is a potential

525 consequence of different physical factors and biometric allometry across scales. Water moves via

526 diffusion in small-scale ( $\mu \mathrm{m}$ to $\mathrm{mm}$ ) boundary layers close to coral surfaces, and moves by

527 advection at larger scales $(\mathrm{m})$ due to wave motion and currents passing over reefs (Barott \&

528 Rohwer, 2012). A change in mechanisms from small to large scales likely leads to scale-

529 dependent evolution of calcium carbonate structural architecture that resists water movement

530 (e.g., a single corallite compared to an entire coral reef). In fact, the space-filling dimensions at

531 the coral reef scale displayed similar values to seagrass beds and hard ground patches (Zawada \&

532 Brock, 2009), suggesting that the topography of the underlying substrate is responsible for the

533 increased space-filling dimension at these larger scales. However, these calculations were

534 constrained by the models' resolution, and future methods that implement a continuum of mm to

$535 \mathrm{~km}$ scales will help identify changes in reef space-filling properties over spatial scales. 
537 level where large-scale interactions between coral reefs, sand flats and algae-dominated patches

538 occur. The methods presented here also provide a framework for the study of other marine or

539 even terrestrial systems. For example, crustose coralline algae is an important reef calcifying

540 phototroph that relies on surface area to obtain energy and competes with other benthic

541 organisms including coral. These methods are also applicable to terrestrial systems like forests

542 where trees acquire energy through photosynthesis and obtain nutrients through their roots,

543 which display space-filling properties, while also shunting resources to other trees through

544 mycorrhizal networks (Simard et al., 1997). Therefore, this work is pertinent to organisms or

545 ecological systems that rely on surfaces for energy acquisition and share resources through

546 biological networks.

\section{Conclusions}

549 This study found a significant association between coral geometry and coral competition 550 outcomes, explaining up to $32 \%$ of the variance in a diverse dataset. Losing corals had low

551 surface space-filling dimensions $\left(D_{S}<2\right)$ and displayed patches with no polyps and large

552 peninsulas, while winning corals $\left(D_{S}>2\right)$ were more compact and displayed more complex and 553 rugose surfaces with smaller perimeters. These findings support the hypothesis that larger coral 554 surface, space-filling dimensions favor energy harvesting, and smaller perimeters reduce the 555 invasion of benthic competitors, providing a competitive edge to corals with these properties.

556 This approach also provides a framework to study coral space-filling and benthic competitions at

557 large reef scales along with the study of other organisms or ecological systems that rely on 558 complex surfaces to obtain energy for competition. 
559

\section{Acknowledgements}

561 We thank Mark Hatay for the original artwork that was adapted to generate Figure 1. 
562

563

564

565

566

567

568

569

570

571

572

573

574

575

576

577

578

579

580

581

582

583

584

585

586

587

588

589

590

591

592

593

594

595

596

597

\section{References}

Bachar A., Achituv Y., Pasternak Z., Dubinsky Z. 2007. Autotrophy versus heterotrophy: The origin of carbon determines its fate in a symbiotic sea anemone. Journal of Experimental Marine Biology and Ecology 349:295-298.

De Bakker DM., Meesters EH., Bak RPM., Nieuwland G., Van Duyl FC. 2016. Long-term shifts in coral communities on shallow to deep reef slopes of Curaçao and Bonaire: are there any winners? Frontiers in Marine Science 3:247.

Barott KL., Rodriguez-Mueller B., Youle M., Marhaver KL., Vermeij MJA., Smith JE., Rohwer FL. 2012a. Microbial to reef scale interactions between the reef-building coral Montastraea annularis and benthic algae. Proceedings of the Royal Society B: Biological Sciences 279:1655-1664.

Barott KL., Rohwer FL. 2012. Unseen players shape benthic competition on coral reefs. Trends in microbiology 20:621-8.

Barott K., Williams G., Vermeij M., Harris J., Smith J., Rohwer F., Sandin S. 2012b. Natural history of coral-algae competition across a gradient of human activity in the Line Islands. Marine Ecology Progress Series 460:1-12.

Basillais É. 1997. Coral surfaces and fractal dimensions: a new method. Comptes Rendus de l'Académie des Sciences - Series III - Sciences de la Vie 320:653-657.

Bradbury RH., Reichelt E. 1983. Fractal Dimension of a Coral Reef. 10:169-171.

Burns JHR., Delparte D., Gates RD., Takabayashi M. 2015. Integrating structure-from-motion photogrammetry with geospatial software as a novel technique for quantifying 3D ecological characteristics of coral reefs. PeerJ 2015:e1077.

Buss LW., Jackson JBC. 1979. Competitive Networks: Nontransitive Competitive Relationships in Cryptic Coral Reef Environments. The American Naturalist 113:223-234.

Castillo KD., Ries JB., Bruno JF., Westfield IT. 2014. The reef-building coral Siderastrea siderea exhibits parabolic responses to ocean acidification and warming. Proceedings of the Royal Society B: Biological Sciences 281:20141856.

Chornesky EA., Williams SL. 1983. Distribution of sweeper tentacles on Montastrea cavernosa. In: The Ecology of Deep and Shallow Reefs, ML Reaka, ed. Symp. Ser. Undersea Res., NOAA Nat. Undersea Res. Prog. 61-67.

Cross SS., Start RD., Silcocks PB., Bull AD., Cotton DWK., Underwood JCE. 1993. Quantitation of the renal arterial tree by fractal analysis. The Journal of Pathology 170:479484.

Efron B., Tibshirani R. 1994. An introduction to the bootstrap.

Faitg J., Davey T., Turnbull DM., White K., Vincent AE. 2020. Mitochondrial morphology and function: two for the price of one! Journal of Microscopy 278:89-106. 
598 Falconer KJ. 2003. Fractal geometry: mathematical foundations and applications. Wiley.

599 Ferrari R., Figueira WF., Pratchett MS., Boube T., Adam A., Kobelkowsky-Vidrio T., Doo SS., 600 Atwood TB., Byrne M. 2017. 3D photogrammetry quantifies growth and external erosion of 601

602

603

604 605

606

607

608

609

610

611

612

613

614

615

616

617

618

619

620

621

622

623

624

625

626

627

628

629

630

631

632

633 individual coral colonies and skeletons. Scientific Reports 7:1-9.

Ferrari R., Gonzalez-Rivero M., Mumby P. 2012. Size matters in competition between corals and macroalgae. Marine Ecology Progress Series 467:77-88.

Fukunaga A., Burns JHR. 2020. Metrics of coral reef structural complexity extracted from 3D mesh models and digital elevation models. Remote Sensing 12:2676.

Fukunaga A., Burns J., Craig B., Kosaki R. 2019. Integrating Three-Dimensional Benthic Habitat Characterization Techniques into Ecological Monitoring of Coral Reefs. Journal of Marine Science and Engineering 7:27.

Galtier d'Auriac I., Quinn RA., Maughan H., Nothias L-F., Little M., Kapono CA., Cobian A., Reyes BT., Green K., Quistad SD., Leray M., Smith JE., Dorrestein PC., Rohwer F., Deheyn DD., Hartmann AC. 2018. Before platelets: the production of platelet-activating factor during growth and stress in a basal marine organism. Proceedings of the Royal Society B: Biological Sciences 285:20181307.

Gracias N., Santos-Victor J. Underwater mosaicing and trajectory reconstruction using global alignment. In: MTS/IEEE Oceans 2001. An Ocean Odyssey. Conference Proceedings (IEEE Cat. No.01CH37295). Marine Technol. Soc, 2557-2563.

Gracias N., Santos-Victor J. 2000. Underwater Video Mosaics as Visual Navigation Maps. Computer Vision and Image Understanding 79:66-91.

Haas AF., Fairoz MFM., Kelly LW., Nelson CE., Dinsdale EA., Edwards RA., Giles S., Hatay M., Hisakawa N., Knowles B., Lim YW., Maughan H., Pantos O., Roach TNF., Sanchez SE., Silveira CB., Sandin S., Smith JE., Rohwer F. 2016. Global microbialization of coral reefs. Nature Microbiology 1:16042.

Halley JM., Hartley S., Kallimanis AS., Kunin WE., Lennon JJ., Sgardelis SP. 2004. Uses and abuses of fractal methodology in ecology. Ecology Letters 7:254-271.

Hatcher GA., Warrick JA., Ritchie AC., Dailey ET., Zawada DG., Kranenburg C., Yates KK. 2020. Accurate Bathymetric Maps From Underwater Digital Imagery Without Ground Control. Frontiers in Marine Science 7:525.

Helander HF., Fändriks L. 2014. Surface area of the digestive tract-revisited. Scandinavian Journal of Gastroenterology 49:681-689.

Henry L-A., Hart M. 2005. Regeneration from Injury and Resource Allocation in Sponges and Corals - a Review. International Review of Hydrobiology 90:125-158.

Holmes G. 2008. Estimating three-dimensional surface areas on coral reefs. Journal of Experimental Marine Biology and Ecology 365:67-73. 
634 Hughes TP. 1989. Community Structure and Diversity of Coral Reefs: The Role of History. 635 Ecology 70:275-279.

636 Jackson JBC. 1977. Competition on Marine Hard Substrata: The Adaptive Significance of 637 Solitary and Colonial Strategies. The American Naturalist 111:743-767.

638 Jackson J. 1979. Morphological strategies of sessile animals. London: Academic Press.

639 Jackson JBC., Winston JE. 1982. Ecology of cryptic coral reef communities: Distribution and 640 abundance of major groups of encrusting organisms. Journal of Experimental Marine $641 \quad$ Biology and Ecology 57:135-147.

642 James G., Witten D., Hastie T., Tibshirani R. 2000. An introduction to Statistical Learning.

643 Lavy A., Eyal G., Neal B., Keren R., Loya Y., Ilan M. 2015. A quick, easy and non-intrusive 644 method for underwater volume and surface area evaluation of benthic organisms by 3D 645 computer modelling. Methods in Ecology and Evolution:n/a-n/a.

646

647

648

649

650

651

652

653

654

655

656

657

658

659

660

661

662

663

664

665

666

667

668

Leon JX., Roelfsema CM., Saunders MI., Phinn SR. 2015. Measuring coral reef terrain roughness using 'Structure-from-Motion' close-range photogrammetry. Geomorphology 242:21-28.

Liaw A., Wiener M. 2002. Classification and regression by randomForest. $R$ news 2:18-22.

Lirman D. 2001. Competition between macroalgae and corals: effects of herbivore exclusion and increased algal biomass on coral survivorship and growth. Coral Reefs 19:392-399.

Madl P., Witzany G. 2014. How Corals Coordinate and Organize: An Ecosystemic Analysis Based on Biocommunication and Fractal Properties. In: Biocommunication of Animals. Dordrecht: Springer Netherlands, 351-382.

Mandelbrot B. 1983. The fractal geometry of nature.

Manzello DP., Enochs IC., Kolodziej G., Carlton R. 2015. Coral growth patterns of Montastraea cavernosa and Porites astreoides in the Florida Keys: The importance of thermal stress and inimical waters. Journal of Experimental Marine Biology and Ecology 471:198-207.

Mark D. 1984. Fractal dimension of a coral reef at ecological scales: a discussion. Marine Ecology Progress Series 14:293-294.

Martin-Garin B., Lathuilière B., Verrecchia EP., Geister J. 2007. Use of fractal dimensions to quantify coral shape. Coral Reefs 26:541-550.

McCook L., Jompa J., Diaz-Pulido G. 2001. Competition between corals and algae on coral reefs: a review of evidence and mechanisms. Coral Reefs 19:400-417.

Meesters EH., Pauchli W., Bak RPM. 1997. Predicting regeneration of physical damage on a reef-building coral by regeneration capacity and lesion shape. Marine Ecology Progress Series 146:91-99.

Meesters HWG., Wesseling I., Bak RPM. 1996. Partial mortality in three species of reef-building

Peer] reviewing PDF | (2020:08:52432:2:0:NEW 6 Mar 2021) 
corals and the relation with colony morphology. Bulletin of Marine Science.

670

Merks RMH., Hoekstra AG., Kaandorp J a., Sloot PM a. 2004. Polyp oriented modelling of coral growth. Journal of Theoretical Biology 228:559-576.

Muthiga NA., Szmant AM. 1987. The effects of salinity stress on the rates of aerobic respiration and photosynthesis in the hermatypic coral Siderastrea siderea. The Biological Bulletin 173:539-551.

Naumann MS., Niggl W., Laforsch C., Glaser C., Wild C. 2009. Coral surface area quantification-evaluation of established techniques by comparison with computer tomography. Coral Reefs 28:109-117.

Nugues M., Delvoye L., Bak R. 2004. Coral defence against macroalgae: differential effects of mesenterial filaments on the green alga Halimeda opuntia. Marine Ecology Progress Series 278:103-114.

Okie JG. 2013. General models for the spectra of surface area scaling strategies of cells and organisms: fractality, geometric dissimilitude, and internalization. The American naturalist 181:421-39.

Oren U., Benayahu Y., Lubinevsky H., Loya Y. 2001. Colony integration during regeneration in the stony coral Favia favus. Ecology 82:802-813.

Oren U., Rinkevich B., Loya Y. 1997. Oriented intra-colonial transport of C-14 labeled materials during coral regeneration. Marine Ecology - Progress Series 161:117-122.

Panico J., Sterling P. 1995. Retinal neurons and vessels are not fractal but space-filling. The Journal of Comparative Neurology 361:479-490.

Peitgen H-O., Jürgens H., Saupe D. 1992. Chaos and fractals: new frontiers of science. New York: Springer-Verlag.

Porter JW. 1976. Autotrophy, Heterotrophy, and Resource Partitioning in Caribbean ReefBuilding Corals. The American Naturalist 110:731-742.

Purkis S., Riegl B., Dodge R. 2006. Fractal Patterns of Coral Communities: Evidence from Remote Sensing (Arabian Gulf, Dubai, U.A.E.). Marine \& Environmental Sciences Faculty Proceedings, Presentations, Speeches, Lectures.

Reichert J., Backes AR., Schubert P., Wilke T. 2017. The power of 3D fractal dimensions for comparative shape and structural complexity analyses of irregularly shaped organisms. Methods in Ecology and Evolution 8:1650-1658.

Rempel HS., Bodwin KN., Ruttenberg BI. 2020. Impacts of parrotfish predation on a major reefbuilding coral: quantifying healing rates and thresholds of coral recovery. Coral Reefs 39:1441-1452.

Rinkevich B., Loya Y. 1983. Oriented translocation of energy in grafted reef corals. Coral Reefs $1: 243-247$. 
705

706

707

708

709

710

711

712

713

714

715

716

717

718

719

720

721

722

723

724

725

726

727

728

729

730

731

732

733

734

735

736

737

738

739

740

741

Roach TNF., Little M., Arts MGI., Huckeba J., Haas AF., George EE., Quinn RA., CobiánGüemes AG., Naliboff DS., Silveira CB., Vermeij MJA., Kelly LW., Dorrestein PC., Rohwer F. 2020. A multiomic analysis of in situ coral-turf algal interactions. Proceedings of the National Academy of Sciences:201915455.

Roth MS. 2014. The engine of the reef: Photobiology of the coral-algal symbiosis. Frontiers in Microbiology 5.

Scheufen T., Iglesias-Prieto R., Enríquez S. 2017. Changes in the Number of Symbionts and Symbiodinium Cell Pigmentation Modulate Differentially Coral Light Absorption and Photosynthetic Performance. Frontiers in Marine Science 4:309.

Schweinsberg M., Weiss LC., Striewski S., Tollrian R., Lampert KP. 2015. More than one genotype: how common is intracolonial genetic variability in scleractinian corals? Molecular Ecology 24:2673-2685.

Sebens KP. 1982. Competition for Space: Growth Rate, Reproductive Output, and Escape in Size. The American Naturalist 120:189-197.

Silveira CB., Luque A., Roach TN., Villela H., Barno A., Green K., Reyes B., Rubio-Portillo E., Le T., Mead S., Hatay M., Vermeij MJ., Takeshita Y., Haas A., Bailey B., Rohwer F. 2019. Biophysical and physiological processes causing oxygen loss from coral reefs. eLife 8.

Simard SW., Perry DA., Jones MD., Myrold DD., Durall DM., Molina R. 1997. Net transfer of carbon between ectomycorrhizal tree species in the field. Nature 388:579-582.

Sous D., Bouchette F., Doerflinger E., Meulé S., Certain R., Toulemonde G., Dubarbier B., Salvat B. 2020. On the small-scale fractal geometrical structure of a living coral reef barrier. Earth Surface Processes and Landforms:esp.4950.

Swierts T., Vermeij MJ. 2016. Competitive interactions between corals and turf algae depend on coral colony form. PeerJ 4:e1984.

Tanner JE. 1995. Competition between scleractinian corals and macroalgae: An experimental investigation of coral growth, survival and reproduction. Journal of Experimental Marine Biology and Ecology 190:151-168.

Toth LT., Stathakopoulos A., Kuffner IB., Ruzicka RR., Colella MA., Shinn EA. 2019. The unprecedented loss of Florida's reef-building corals and the emergence of a novel coral-reef assemblage. Ecology 100.

Warner ME., Fitt WK., Schmidt GW. 1996. The effects of elevated temperature on the photosynthetic efficiency of zooxanthellae in hospite from four different species of reef coral: A novel approach. Plant, Cell and Environment 19:291-299.

Young GC., Dey S., Rogers AD., Exton D. 2017. Cost and time-effective method for multi-scale measures of rugosity, fractal dimension, and vector dispersion from coral reef $3 \mathrm{D}$ models. PLOS ONE 12:e175341.

Zawada DG., Brock JC. 2009. A Multiscale Analysis of Coral Reef Topographic Complexity

Peer) reviewing PDF | (2020:08:52432:2:0:NEW 6 Mar 2021) 
742 Using Lidar-Derived Bathymetry. Journal of Coastal Research 10053:6-15.

743 Zawada KJA., Dornelas M., Madin JS. 2019. Quantifying coral morphology. Coral Reefs 744 38:1281-1292.

745 


\section{Figure 1}

Coral competition outcomes and coral geometry methods.

(A) The three possible outcomes of the coral competition are illustrated for the coral species Orbicella faveolata. In the left panel (winning), the coral overgrows the algae; notice the proliferation of new polyps at the perimeter of the coral. In the middle panel (neutral) neither coral nor algae is overgrowing one another. In the right panel, the algae are overgrowing the coral (losing) and coral skeleton is visible under the algae. (B) Curaçao site locations and coral species studied. (C) Coral colonies were photographed in situ. Close-range, overlapping pictures were stitched together to generate high-resolution 2D perimeter models. Outlines of the $2 \mathrm{D}$ coral perimeters were used to calculate the percentage of perimeter winning, losing and remaining neutral to competitors and to calculate the perimeter length and space-filling dimension over a $0.1 \mathrm{~mm}$ to $1 \mathrm{~m}$ scale range. Photogrammetry methods were used to create 3D coral models, and non-coral mesh was removed to measure coral surface and perimeter space-filling dimension, surface area, perimeter length and volume. 


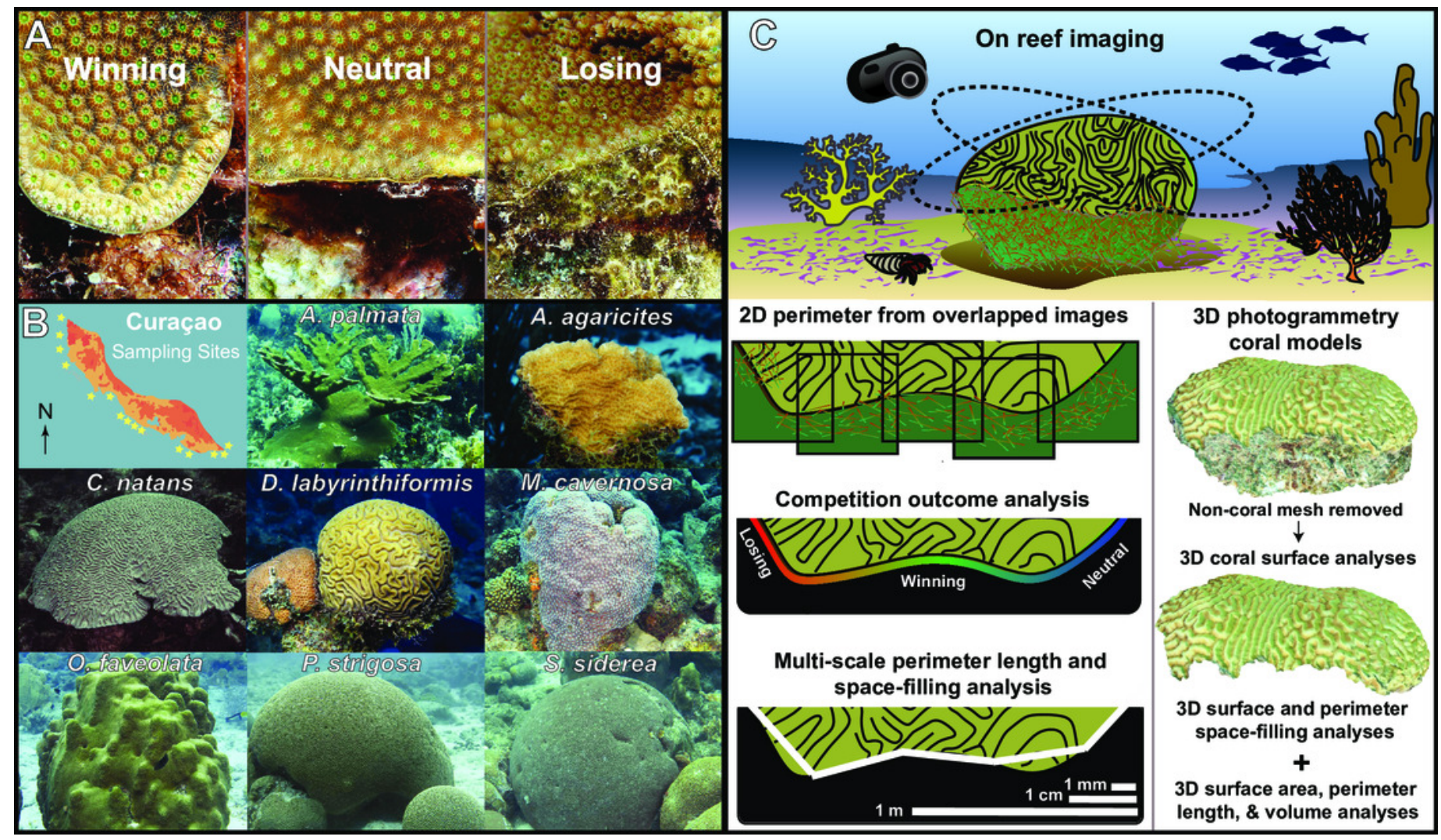




\section{Figure 2}

Coral models and statistics for competitive outcomes.

(A) 2D coral perimeter models and 3D coral models with different percentages of losing perimeter (\%L). Losing regions along the $2 \mathrm{D}$ perimeter projections are highlighted in red. (B) Box plots of the three perimeter outcomes: losing $(\% \mathrm{~L})$, neutral $(\% \mathrm{~N})$, and winning $(\% \mathrm{~W})$. The middle line corresponds to the median, the range of the box contains the $25^{\text {th }}$ to the $75^{\text {th }}$ percentile, and each whisker is the minimum (in absolute value) between the $150 \%$ interquartile range (IQR) and the value of the most extreme point on that side of median. Outliers exceeding the whiskers are included (Table S2). (C) Bar chart of competitive outcomes for species with $n \geq 5$. Bars show the average percentage of losing perimeter (black), winning perimeter (dark grey), and neutral perimeter (light grey). 

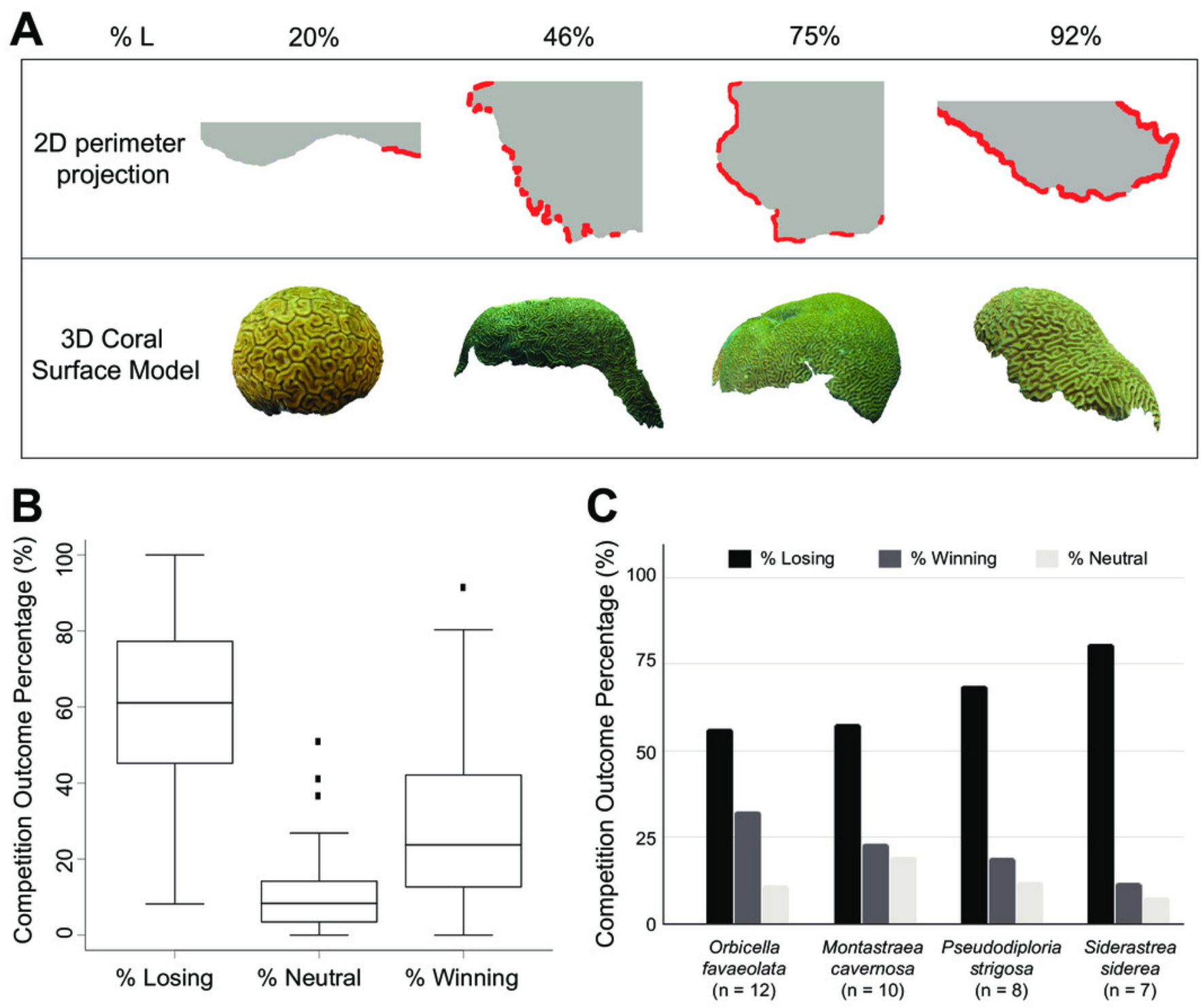


\section{Figure 3}

Coral surface and perimeter space-filling dimensions.

(A) Plot of coral surface (top) and perimeter (bottom) space-filling dimensions with the means (black dots), 5-95\% confidence intervals (whiskers), and labels associated with each coral sample. The solid line provides a reference for the Euclidean dimensions: $\mathrm{ED}_{\mathrm{p}}=1$ (perimeter) and $\mathrm{ED}_{\mathrm{s}}=2$ (surface). The mean values for the space-filling dimension of the perimeter $\left(D_{\mathrm{p}}\right)$ and the surface $\left(D_{s}\right)( \pm$ standard deviation) and their respective coefficients of variation (CV = standard deviation $/$ mean * 100 ) are also included. (B) Two-dimensional coral perimeter models displaying space-filling dimensions below the Euclidean dimension. (C) Threedimensional coral models associated with high, medium, and low space-filling dimensions for the coral surface. Empty spaces or holes in the 3D models show loss of coral tissue where the polyps have died or are overgrown by competing organisms. 


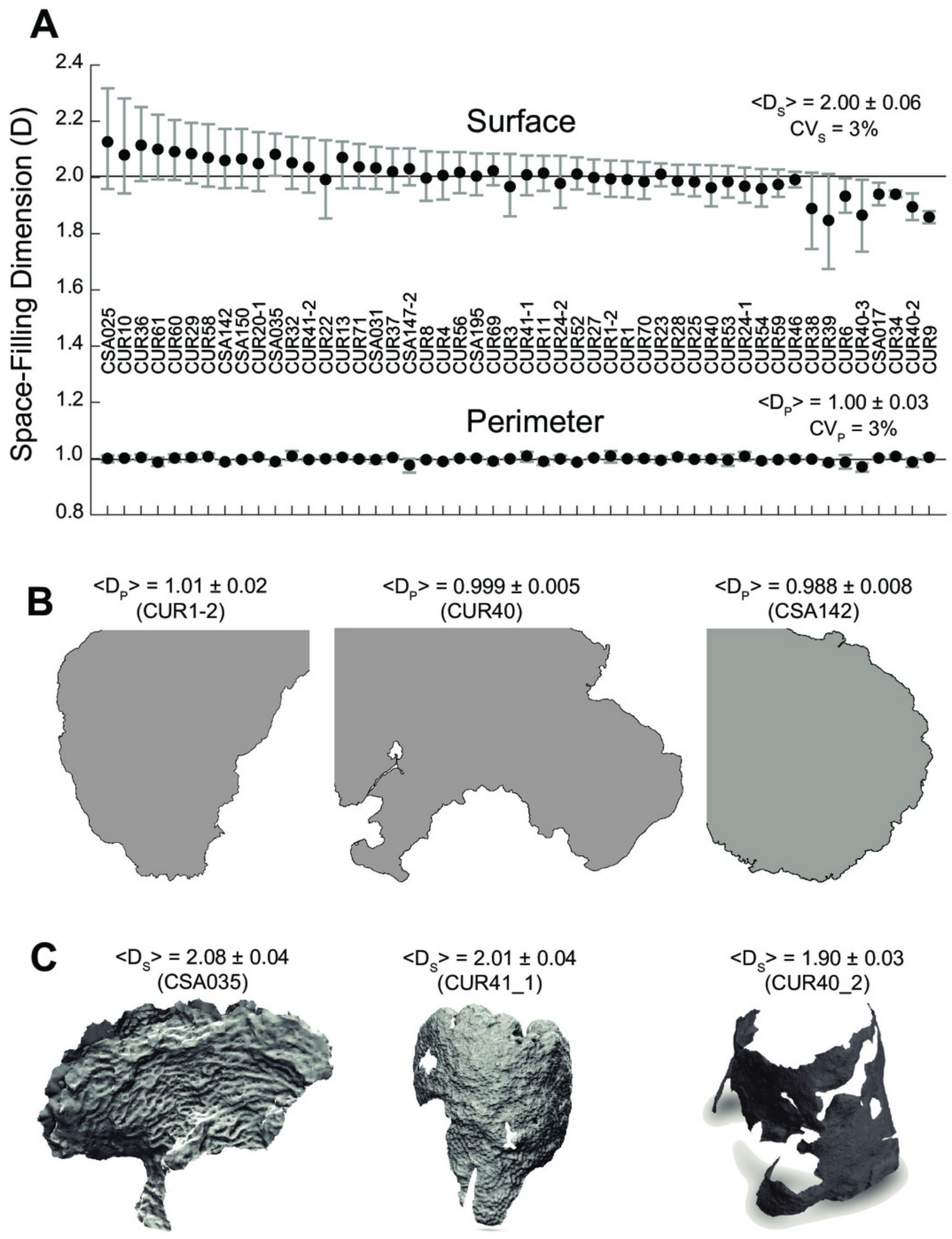




\section{Figure 4}

Relationships between coral geometry and coral competition outcomes: univariate and multivariate analyses.

The left panel of graphs relate to the percentage of losing perimeter $(\% \mathrm{~L})$ and the right panel of graphs relate to the percentage of winning perimeter (\%W). (A) and (B) Coral competition outcome as a function of the surface space-filling dimension with a linear regression fitted using the least-squares method. Coral surface space-filling dimension is the best single indicator of coral competition outcomes. (C) and (D) Bottom-up random forest model construction of coral geometric variables with the explained variance plotted as each variable is added. The solid black line corresponds to the average variance explained (\%), and the grey area represents the $95 \%$ confidence interval. (E) and (F) Variable selection likelihood maps where the frequency (\%) of the selected variable is shown. Frequencies range from $0 \%$ (white) to $100 \%$ (black). Variables include surface space-filling dimension $\left(D_{S}\right)$, perimeter from 3D models $\left(P_{30}\right)$, species $(S)$, 3D perimeter-to-surface area ratio $\left(P_{30} / S A\right)$, depth (d), volume-to-surface area (V/SA), polyp diameter $\left(\mathrm{P}_{\mathrm{d}}\right)$, volume $(\mathrm{V})$, 2D perimeter-tosurface area ratio $\left(\mathrm{P}_{\mathrm{R}} / \mathrm{SA}\right)$, surface area $(\mathrm{SA})$, surface area-to-polyp area ratio $\left(\mathrm{SA}_{\text {polyp }}\right), 3 \mathrm{D}$ perimeter-to-polyp size ratio $\left(P_{\text {polyp }}\right)$, perimeter from $2 \mathrm{D}$ models $\left(P_{R}\right)$, and perimeter spacefiling dimension $\left(D_{p}\right)$. 
$\%$ Losing
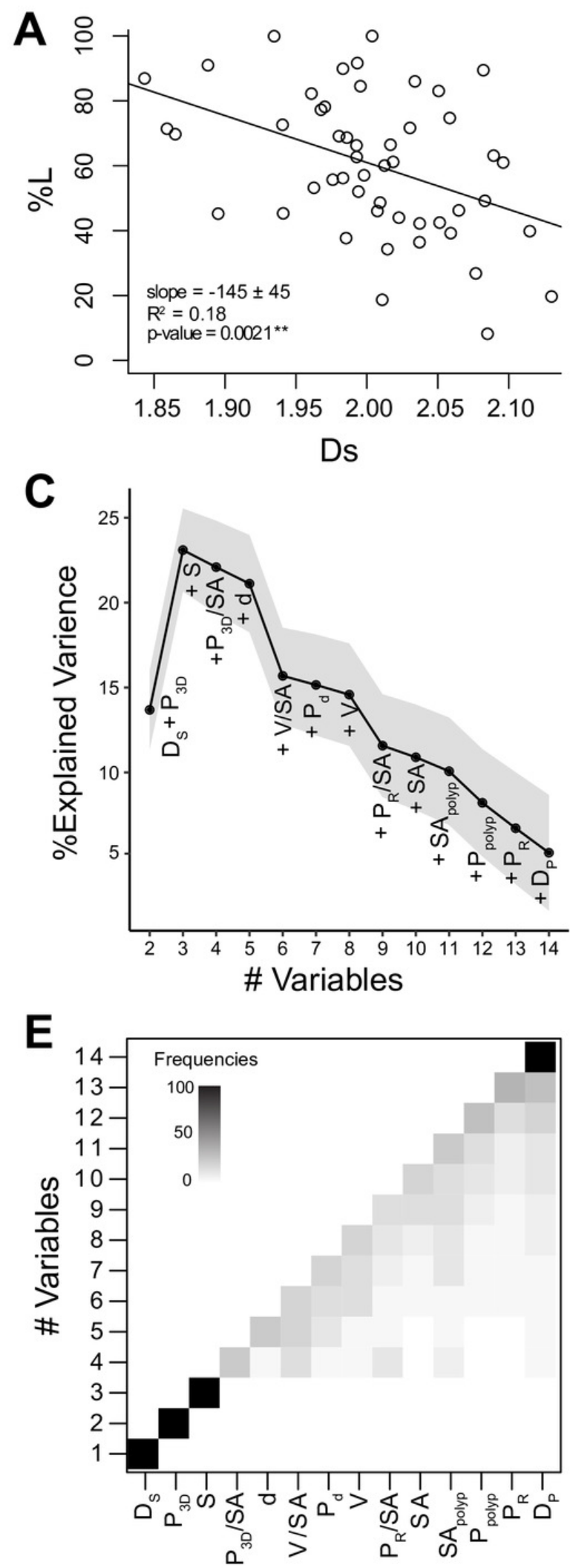

Selected Variables
$\%$ Winning
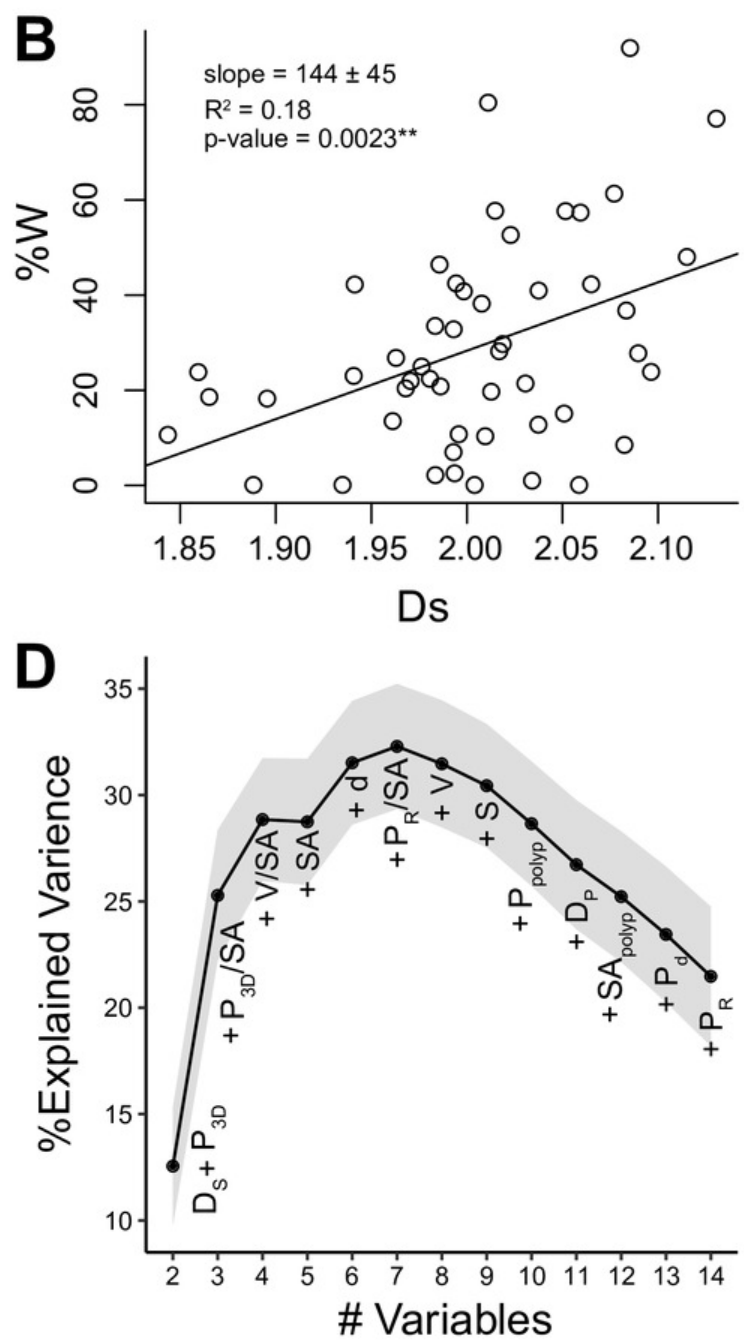

$F$

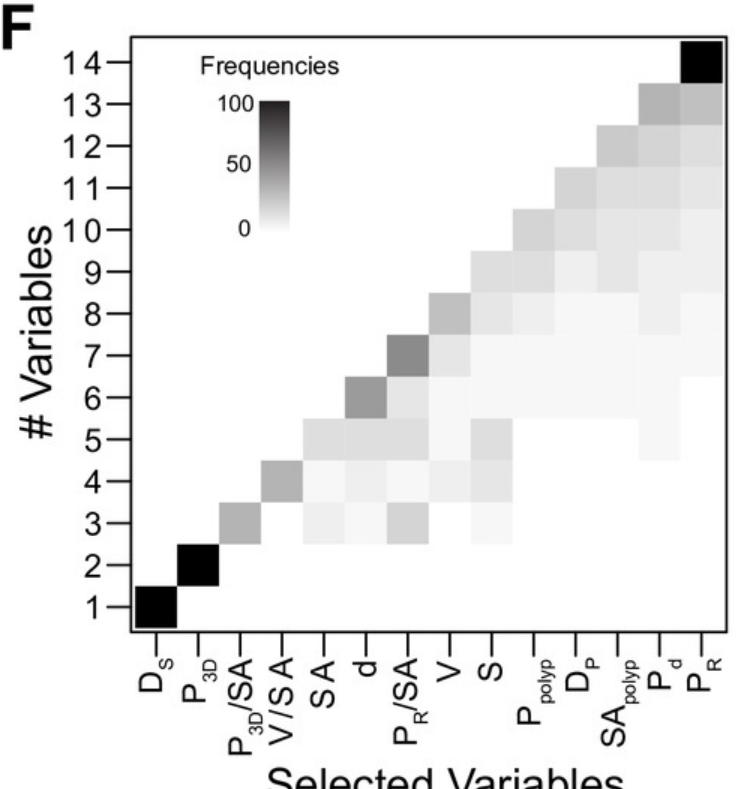




\section{Figure 5}

Interdependence of optimal variables in the predictions of outcomes.

Average regression trees generated for the percentage of $(A)$ losing perimeter $(\% \mathrm{~L})$ and $(B)$ winning perimeter (\%W) including the selected variables in the refined random forest analysis (Figure 4). Each cluster displays the average outcome and the value below the box indicates the percentage of data contained in the cluster. The intensity of blue is proportional to $\% \mathrm{~L}$ and the intensity of green is proportional to $\% \mathrm{~W}$. Variables include the perimeter length from 3D models $\left(P_{30}\right)$ and the coral surface space-filling dimension $\left(D_{s}\right)$.

A Losing perimeter $(\% \mathrm{~L})$

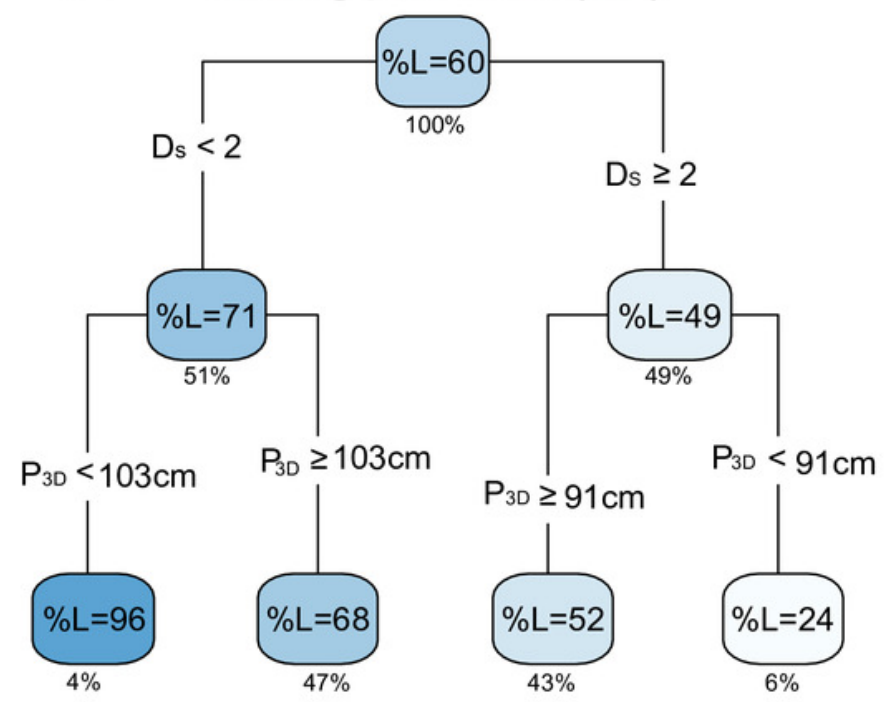

B Winning perimeter $(\% \mathrm{~W})$

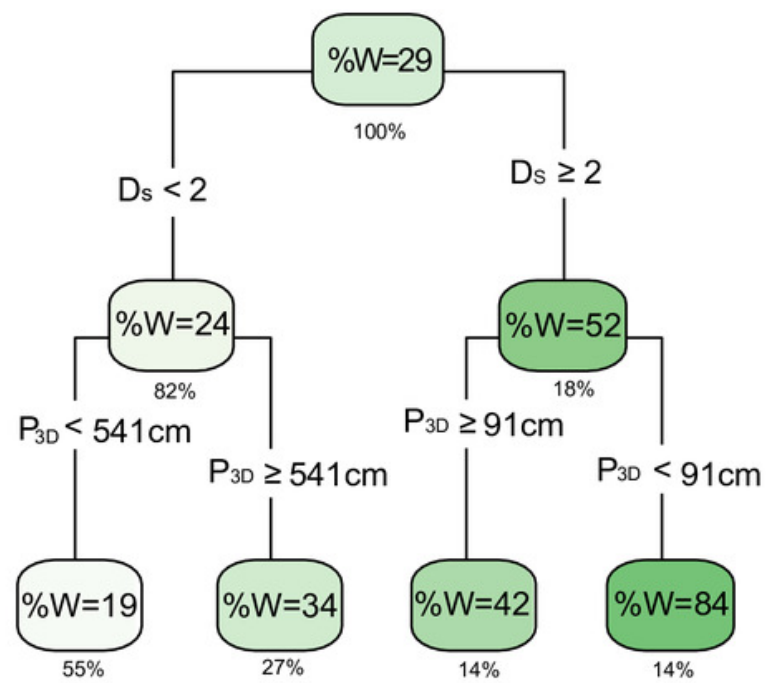




\section{Figure 6}

Coral space-filling dimension from corallite to reef scales.

The plot shows the range of space-filling dimensions measured across various scales from different coral studies. The space-filling dimensions are grouped in two categories: Surface space-filling dimension (dark grey) and perimeter space-filling dimension (light grey). For the perimeter, the ranges correspond to coral colonies (current study - box-counting method), larger coral colonies (Bradbury \& Reichelt, 1983; Mark, 1984 - step-counting method), and coral reefs (Purkis et al., 2006 - box-counting method). For the surface, the ranges correspond to corallite texture (Martin-Garin et al., 2007 - box-counting method), corallite structure (Martin-Garin et al., 2007 - box-counting method), coral colonies (current study box-counting method), and coral reefs (Zawada et al., 2009 - variation method). 


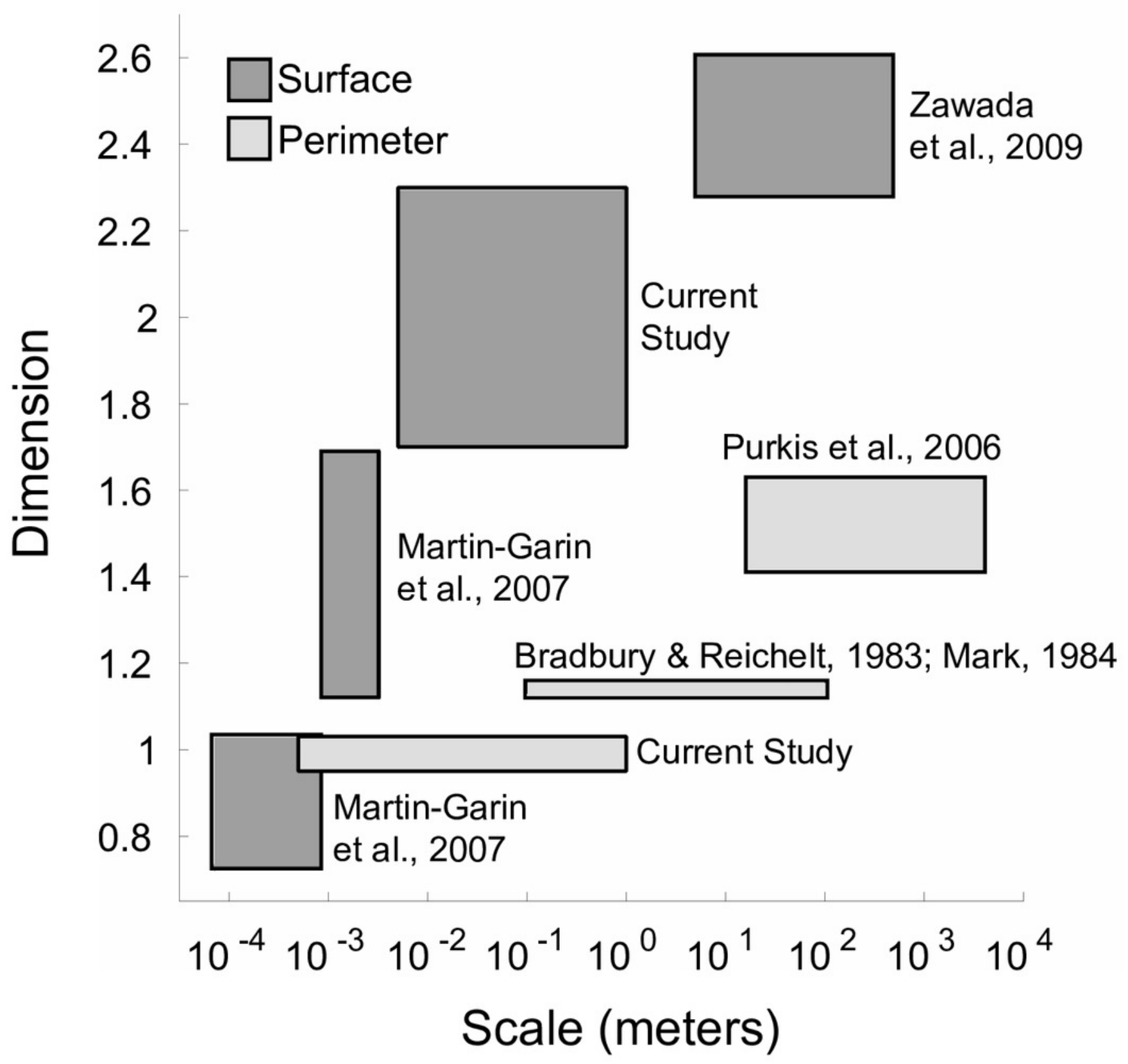

